\title{
Cardiac beta-defensins upregulate with a high fat diet and influence monocyte migration*
}

\author{
Annika Linde ${ }^{1,2}$, Christopher Ross ${ }^{3}$, Frank Blecha ${ }^{1}$, Gerald H. Lushington ${ }^{4}$, Tonatiuh Melgarejo ${ }^{1,2 \#}$ \\ ${ }^{1}$ Department of Anatomy \& Physiology, Kansas State University, Manhattan, USA \\ ${ }^{2}$ Department of Human Nutrition, Kansas State University, Manhattan, USA \\ ${ }^{3}$ Center for Veterinary Health Sciences, Oklahoma State University, Stillwater, USA \\ ${ }^{4}$ Department of Medicinal Chemistry, University of Kansas, Lawrence, USA \\ Email: "tmelgare@ksu.edu \\ Received 13 April 2013; revised 14 May 2013; accepted 21 May 2013 \\ Copyright (C) 2013 Annika Linde et al. This is an open access article distributed under the Creative Commons Attribution License, \\ which permits unrestricted use, distribution, and reproduction in any medium, provided the original work is properly cited.
}

\begin{abstract}
Inflammation plays a central role in development of cardiovascular pathology, and enhanced understanding of the innate immune response will help direct novel therapeutic strategies to address heart disease. Host defense peptides (HDPs) - hereunder defensins - exhibit antimicrobial, chemotactic, tissue healing and other key biological properties. Beta-defensin expression in whole-heart-homogenate has been reported in different species, and plasma alpha-defensins have been associated with cardiovascular morbidity and mortality. Still, the role of defensins in cardiac pathophysiology remains widely undetermined. Here, we show that a subset of rat-beta-defensins (rBDs) is constitutively expressed in the myocardium, and that their gene-expression level is influenced by systemic exposure to inflammatory mediators (highfat-diet and lipopolysaccharide). Using synthetic analogues of select rBD peptides, we evaluated the antimicrobial activity of these HDPs against clinically relevant pathogens and their ability as immunoregulatory compounds. We found that an innate myocardial response that involves rBDs is activated by highfat-diet feeding in rats, and that these HDPs influence monocyte migration-findings that suggest the peptides respond to exogenous danger-signals, and act within the context of a myocardial "first-line-of-defense".
\end{abstract}

Keywords: Antimicrobial Peptides; Myocardial; Endotoxin; Dietary Lipid; Cell Migration

\section{INTRODUCTION}

Defensins are small cationic host defense peptides (HDPs)

\footnotetext{
"The authors declare no conflicts of interest.

${ }^{*}$ Corresponding author.
}

with a broad functional repertoire that position them as central players within the context of an innate immune response $[1,2]$. Several studies have in recent years reported on pattern recognition receptors (TLRs), signaling pathways (NF $\kappa \mathrm{B})$, as well as different effector molecules relevant to an innate immune response (e.g. cytokines and defensins) expressed intrinsically by the cardiovascular system, as previously reviewed [3]. Altogether these findings support that the heart is capable of establishing a local innate defense response, and as such is not solely positioned at the mercy of classical immune cells' efficacy at fighting off pathogens and other injurious danger elements. Beta-defensins (BDs) are generally considered natural antimicrobial peptides of epithelial origin, while other HDPs, such as cathelicidins and alpha-defensins, are typically associated with circulatory and bone-marrow cells [2]. However, different studies have screened for beta-defensin expression in a range of tissues from various species and described expression of BD1, BD2, and BD3 in whole heart homogenate [4-12]. Alpha-defensin peptides have been implicated in the progression of hyperlipidemia and atherosclerosis [13-16], while betadefensins' putative role within the cardiovascular system is largely unexplored. Inflammation, conceptually acting to protect against injurious stimuli, has been also recognized as a key factor in the development and progression of cardiovascular disease (CVD) $[15,17,18]$. An improved understanding of factors underlying this undesirable hyper-inflammatory process is thus of immediate importance to design novel preventative and therapeutic strategies aimed towards diseases of the heart and vasculature. The purpose of the study was to determine whether the myocardial gene-expression of one type of host defense peptides (beta-defensins) is influenced by inflammation. The role played by certain lipoproteins in atherosclerotic CVD has been confirmed in clinical trials [19], and en- 
dotoxemia is a known risk factor in development of cardiac pathology [20]. We consequently studied the effect of an infectious (lipopolysaccharide, LPS) versus a noninfectious (high fat diet, HFD) inflammatory mediator on cardiac rBD gene-expression levels. Moreover, we assessed the functional role, including antimicrobial activity and impact on cell migration, of a subset of these newly identified heart host defense peptides. Our data supports that inflammation affects cardiac rBD expression, and suggest that these peptides play an active biological role in intrinsic heart host defense.

\section{MATERIALS \& METHODS}

\subsection{Study Group}

Male Sprague-Dawley rats (Charles River, Wilmington, MA) were divided into groups: 1) Lipopolysaccharide exposure (LPS), 2) High fat diet feeding (HFD), and 3) Control group (C). All experimental protocols were preapproved by the Kansas State University IACUC.

\subsection{Exposure to Inflammatory Mediators}

One group (LPS) was exposure to LPS (Escherichia coli (O127:B8); Sigma-Aldrich, St. Louis, MO) at $10 \mathrm{mg} / \mathrm{kg}$ IP per animal, and observed for 48 hours until end-point. A second group (HFD) was fed a high fat (33.8\%) diet (TD.97070, Harlan Teklad Research Diets, Madison, WI) for three weeks. LPS and Control groups were fed a standard rat chow diet.

\subsection{Measurement of Serum Markers}

Whole blood was collected at baseline, 12, and 36 hours for all groups, and at 7 and 21 days for the HFD and Control groups. Commercially available ELISA kits were used for assessment of serum HDL and LDL Cholesterol Quantification (BioVision, Mountain View, CA), Rat CReactive Protein and Cardiac Troponin I (Life Diagnostics, West Chester, PA). Cytokine levels were measured using the Bio-Plex Rat Cytokine 9-plex Panel (BioRad, Hercules, CA) and a Luminex ${ }^{\circledR} 100^{\mathrm{TM}}$ platform (Invitrogen, Carlsbad, CA).

\subsection{Myocardial Beta-Defensin Expression}

Myocardial RNA was extracted using a RiboPure ${ }^{\mathrm{TM}}$ Kit (Ambion, Austin, TX), and quantity/quality assessed using a NanoDrop Spectrophotometer (Wilmington, DE) and an Agilent 2100 BioAnalyzer (Santa Clara, CA), respectively. Myocardial gene-expression of select rat betadefensins was assessed through qRT-PCR (BioRad iCycler), using a customized RT2Profiler PCR Array (SuperArray, Frederick, MD). Sequences were obtained from the Rat Genome Database (http://rgd.mcw.edu/) (Table 1). E-Gel ${ }^{\circledR}$ Agarose Gels (Invitrogen, Carlsbad, CA) were used to verify amplicon sizes of the PCR products.

Table 1. Cardiac rat beta-defensin primer sequences.

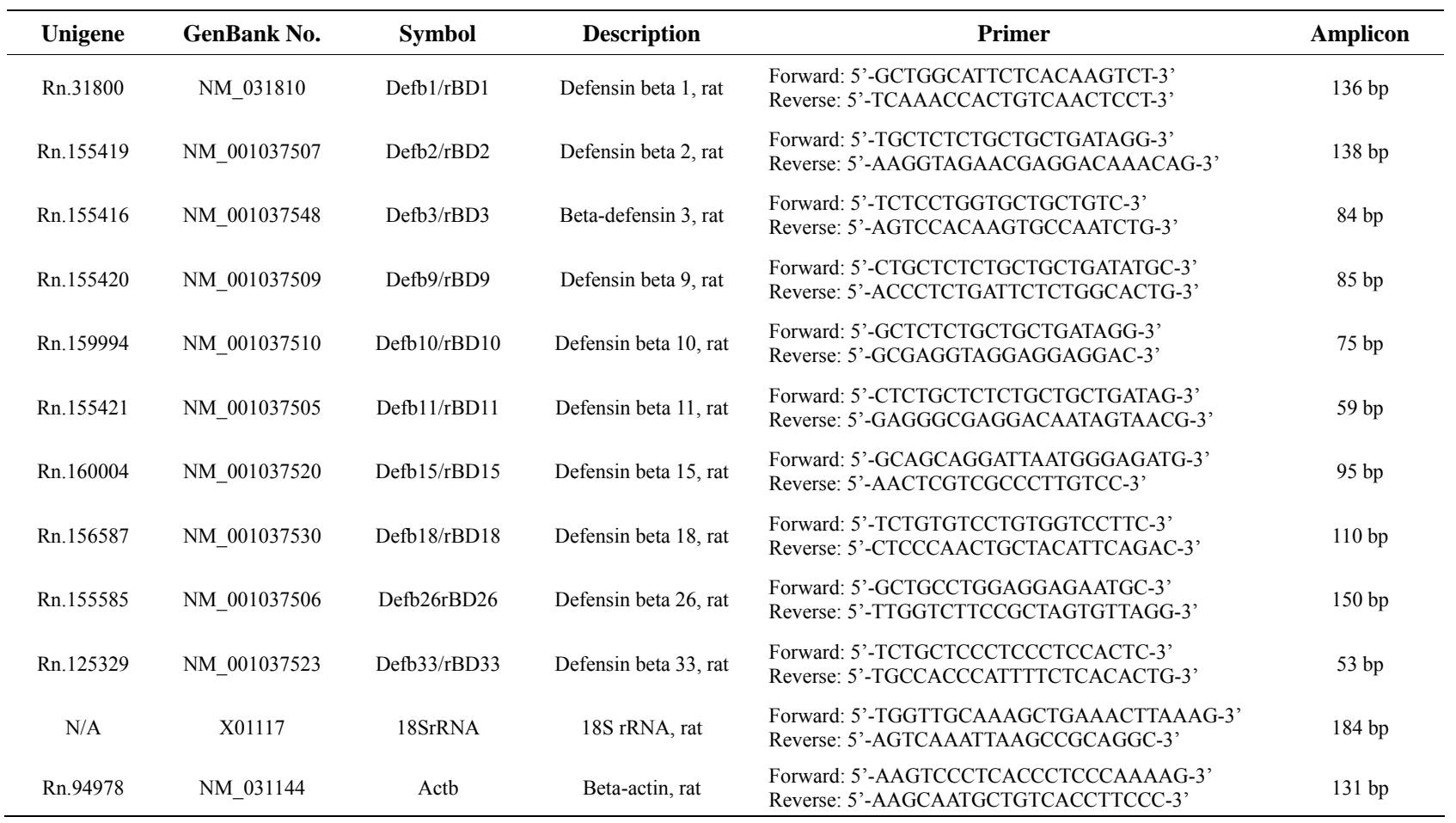

The table includes an overview of primers (forward and reverse) for ten predicted rBD sequences derived from the Rat Genome Database, and two housekeeping genes (Actb and 18S). Primers were designed using Beacon Designer software (Premier Biosoft, Palo Alto, CA). 


\subsection{Peptide Synthesis of Select rBDs}

Three 32-amino acid peptides spanning the rBD cysteine motif were chemically synthesized (Structural Biology Center, University of Kansas, KS). The material eluted as single peaks on RP-HPLC, and peptide-identity was confirmed by mass spectroscopy. Peptides were lyophilized and dissolved in $0.01 \%$ acetic acid $(3 \mathrm{mg} / \mathrm{ml})$ as stock solutions. Peptide sequences are included below:

rBD10: CRLFEGFCHDKNCPPPTSHVGSCHPEKRSCCK; rBD11: CHSKGGYCYRYYCPRPHRRLGSCYPYAANCCR; rBD33: CEKMGGICKYQKTHGCSILPAECKSRYKHCCR.

\subsection{Computational Homology Modeling}

Cross-species alignment in CLUSTALW [21] was used for target structure-prediction, and subsequent modeling performed in Modeller [22]. Analysis of rBD secondary structures and surface characteristics was performed using SYBYL 6.9.2 (TRIPOS, St. Louis, MO).

\subsection{Antimicrobial Activity}

Staphylococcus aureus (ATCC\#10031), Listeria monocytogenes (ATCC\#19115), and E. coli (ATCC\#25922) were grown in Mueller-Hinton-II-broth (BBL-297963. Becton/Dickinson-Company; Sparks, CA), adjusted to 0.5 McFarland-standard $\left(10^{8} \mathrm{CFU} / \mathrm{ml}\right)$, and diluted 1:100. Antimicrobial activity was determined using a CLSI broth micro-dilution method [23,24]. Briefly, $100 \mu \mathrm{l}$ of the rBD solutions were added to a micro-titer plate followed by 1:2 serial-dilution $(50 \mu \mathrm{rBD}$ solution into wells containing $50 \mu \mathrm{l}$ PBS), and subsequent addition of $50 \mu \mathrm{l}$ microbial suspension. Plates were incubated at $37^{\circ} \mathrm{C}$ and $100 \mathrm{rpm}$ for $2 \mathrm{hrs}$, followed by addition of 100 $\mu l$ nutritive broth to individual wells. Antimicrobial activity (minimal inhibitory concentration, MIC) was determined after 24 hours incubation.

\subsection{Cell Migration Assays}

Rat monocytes and neutrophils ( $>90 \%$ purity) were obtained via FACS (Veterinary Diagnostic Laboratory, Kansas State University) to assess the chemo-attractive ability of select rBDs. Cells were suspended in RPMI1640 medium (Life Technologies, Carlsbad, CA) supplemented with $0.1 \%$ BSA to a concentration of 200,000 cells $/ \mathrm{ml}$. Cell migration (50 $\mu \mathrm{l}$ upper well volume) in response to individual rBDs ( $25 \mu \mathrm{l}$ lower well volume, and peptide concentrations ranging from $0.1-10,000 \mathrm{ng} / \mathrm{ml}$ ) versus controls (medium only, or fMLP) was determined using a Neuro Probe AP48 chemotaxis chamber (Boyden) and $25 \times 80 \mathrm{~mm}$ PVP-free polycarbonate membranes with $5 \mu \mathrm{m}$ pore size (Neuro Probe, Inc., Gaithersburg, MD). Chemotaxis assemblies were incubated for $90 \mathrm{~min}$ at $37^{\circ} \mathrm{C}$ and $5 \% \mathrm{CO}_{2}$. Filters were removed after incubation, followed by fixation of migrated cells in methanol, Diff-Quik (Polysciences, Inc., Warrington, PA) staining, and counting of cells via light microscopy in five randomly selected fields (data reported as mean $\pm \mathrm{SD}$; from triplicate wells).

\subsection{Statistical Analysis}

The software GraphPad Prism 5 (San Diego, CA) was used for data-analysis, at a 5\% level of significance. Data is presented as mean $\pm \mathrm{SD}$ unless otherwise stated. The thermocycler-data was analyzed using a SuperArray template for determination of fold-change in genes of interest via the $\Delta \Delta \mathrm{Ct}$ method. Myocardial rBD mRNA expression was analyzed using Student's t-test. Differences in test values between groups over time were assessed by two-way repeated measures analysis of variance (rmANOVA) with post-hoc Bonferroni analysis.

\section{RESULTS}

\subsection{Beta-Defensins Are Constitutively Expressed in the Rat Myocardium}

Through preliminary studies we sought to confirm that cardiomyocytes in fact are responsible for previously reported cardiac beta-defensin-1 expression. We consequently evaluated laser micro-dissected rat cardiomyocytes using the P.A.L.M. system (Carl Zeiss MicroImaging, Bernried, Germany), and could via subsequent downstream analysis (including qRT-PCR and agarose gelelectrophoresis) confirm myocardial beta-defensin-1 expression [25]. To further establish a baseline expression profile for cardiac beta-defensins we then screened whole heart homogenate for the thirty-five predicted rat betadefensin peptide sequences available in the Rat Genome Database (http://rgd.mcw.edu/) using primers designed using Beacon Designer software (PREMIER Biosoft International, Palo Alto, CA). We found that the rat heart exhibit constitutive gene-expression of at least seven betadefensins (rBD1, 3, 10, 11, 15, 18, and 33).

\subsection{High-Fat-Diet Results in Up-Regulation of Cardiac rBD Gene-Expression}

To determine the effect of systemic inflammation on the levels of constitutively expressed cardiac rBDs, we studied one control and two experimental groups subjected to either an infectious (LPS) or a non-infectious (HFD) inflammatory mediator. The gene-expression studies allowed for inclusion of an additional three rBDs (i.e. $\mathrm{rBD} 2, \mathrm{rBD} 9$, and $\mathrm{rBD} 26$ were chosen randomly), while using 18SrRNA and Actb as housekeeping genes. We confirmed high RNA quality on all samples (rRNA-ratio $260 / 280>2$ ) prior to the qRT-PCR runs. Gene-expres- 
sion for all ten rBDs increased secondary to both inflammatory mediators. However, statistically significant upregulation (as compared to control) was only detected in the HFD group for eight of the ten studied cardiac rBDs. The highest fold-difference in gene-expression (HFD group) was noted for rBD10, rBD11 and (thirdly) for rBD33 (Figure 1). RT-PCR products were subsequently assessed by gel electrophoresis, and identified as single bands of anticipated amplicon size. These findings suggest that known inflammatory mediators (particularly a high fat diet) trigger an up-regulation of cardiac host defense peptides-likely contributing to an intrinsic molecular defense of the myocardium against danger signals.

\subsection{Cardiac rBD Up-Regulation Concurs with Elevated Inflammatory Cytokine Levels}

To evaluate serum cytokine response in the experimental groups, we assessed nine different cytokines from rat (IL$1 \alpha / \mathrm{IL}-1 \beta / \mathrm{IL}-2 / \mathrm{IL}-4 / \mathrm{IL}-6 / \mathrm{IL}-10 / \mathrm{GM}-\mathrm{CSF} / \mathrm{IFN}-\gamma / \mathrm{TNF}-\alpha)$ at 0,12 , and 36 hours for all groups, in addition to 7 and 21 days for the HFD and control groups. Serum levels for all nine cytokines were either below detection or lower than baseline values at 7 and 21 days, so only values for the first three time-points are included in Figure 2. No statistical significant difference was identified in baseline cytokine levels among groups. For the LPS group, a statistically significant increase in TNF- $\alpha$, IL- $1 \beta$, IL-6 and IFN $\gamma$ was observed at $12 \mathrm{hrs}$, in addition to an increase in IL-2 and GM-CSF at $36 \mathrm{hrs}$ - consistent with a pro-inflammatory response secondary to LPS exposure. IL-1 $\alpha$ serum levels were increased relatively compared to controls at $36 \mathrm{hrs}$ for both experimental groups (LPS and HFD), yet measuring quantitatively lower compared to baseline-values. The observed increase in serum cytokine levels at baseline is most probably explained by a stress-related response in the animals. An anti-inflammatory response was moreover observed at 12 and 36 hours-indicated by a statistically significant increase in IL-10 serum levels. A statistically significant difference in IL-4 serum levels was also observed at 36 hours for both experimental groups. However, levels were here again quantitatively lower compared to baseline. Collec-

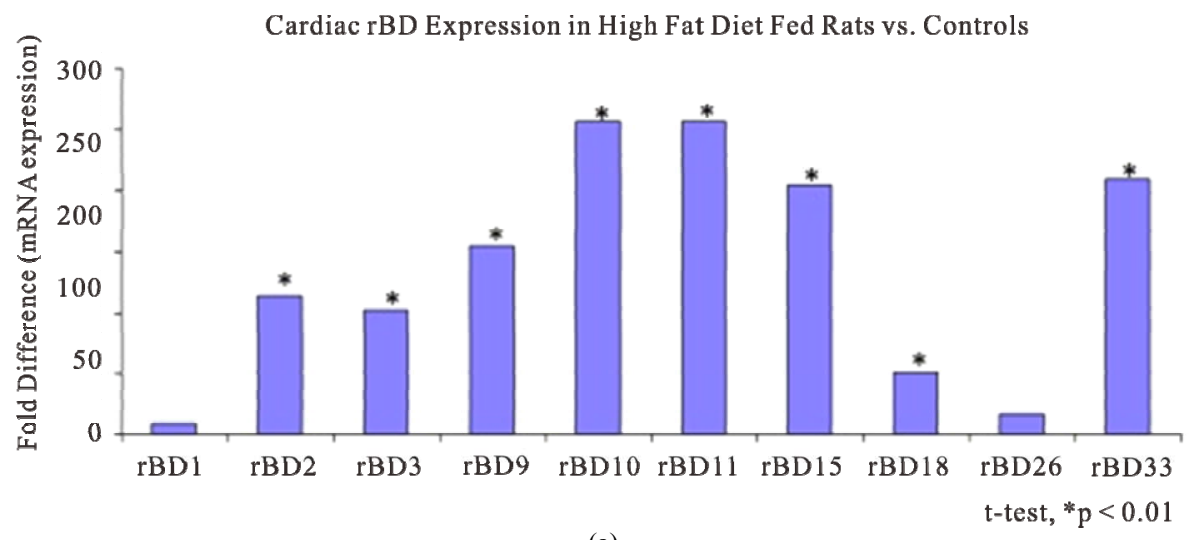

(a)

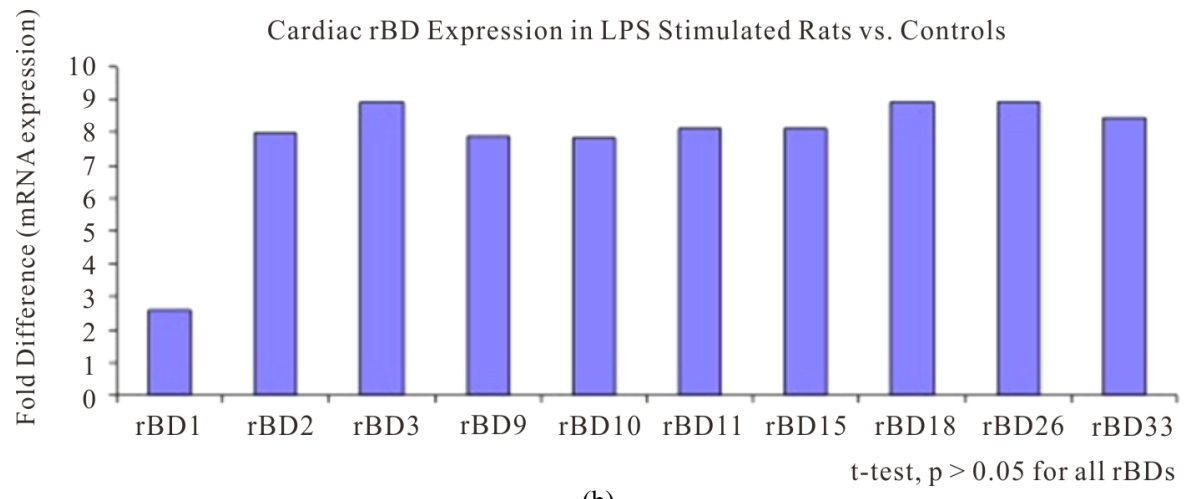

(b)

The graphs display relative myocardial mRNA expression of ten rBDs in response to either HFD feeding (top panel) or LPS administration (lower panel). Fold difference indicates degree of rBD mRNA up-regulation in each experimental group relative to control (e.g. rBD10 and rBD11 mRNA levels are approximately 250 -fold higher in the HFD group compared to controls - based on $C_{t}$ values obtained by qRT-PCR). Focus was thus directed at these peptides for the functional studies.

Figure 1. Myocardial rat beta-defensin mRNA expression levels in inflammation. 

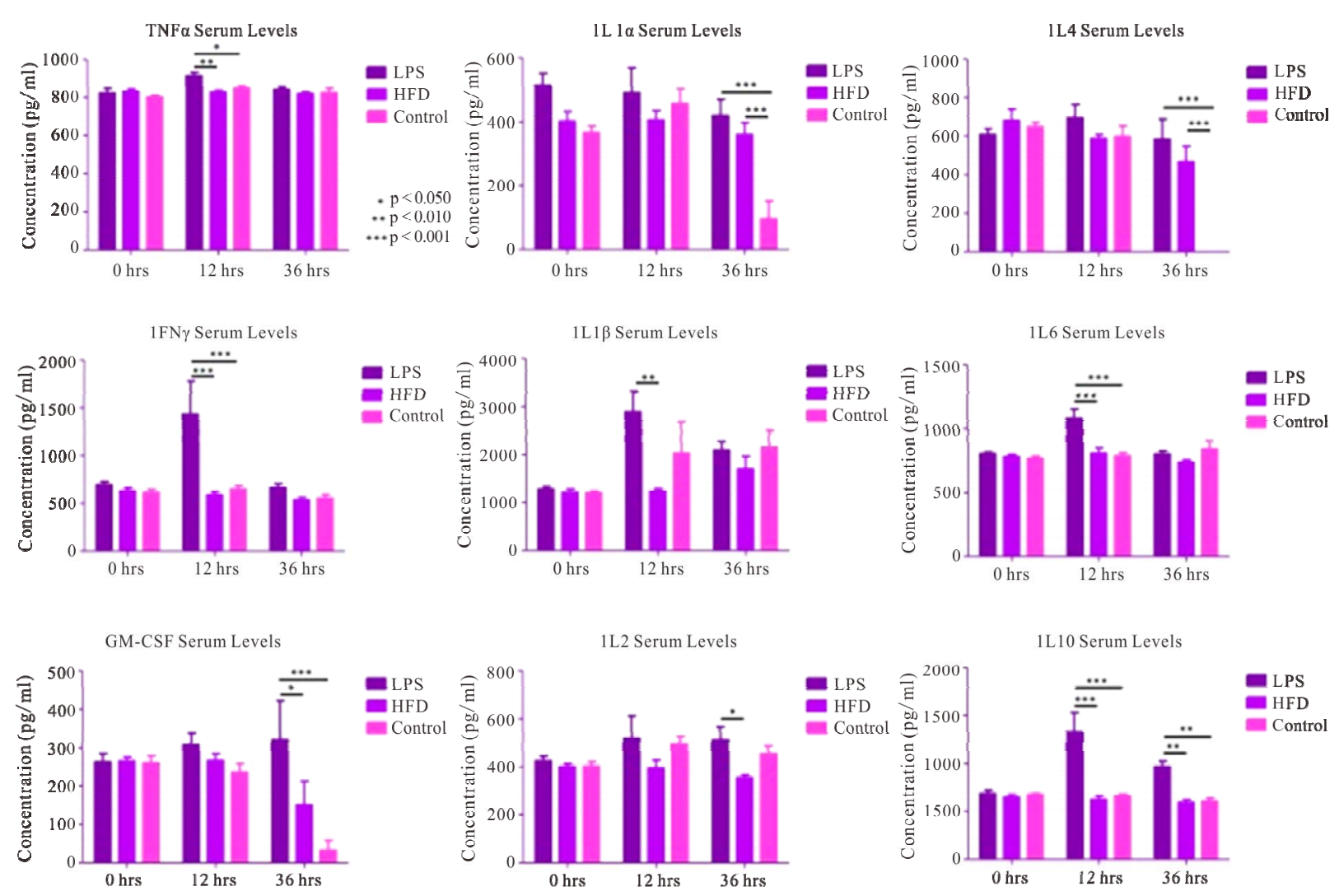

The graphs show circulating levels $(\mathrm{pg} / \mathrm{ml})$ of 9 cytokines in rat serum from two experimental groups (LPS and HFD) and one control group, at baseline (0 hrs), 12 and 36 hours. Abbreviations: LPS: lipopolysaccharide, HFD: high-fat diet, TNF $\alpha$ : tumor necrosis factor alpha, IFN $\gamma$. interferon gamma, GM-CSF: granulocyte/monocyte colony-stimulating factor, IL1 $\alpha /$ IL1 $\beta$ : interleukin-1 alpha/beta, IL2: interleukin-2, IL4: interleukin-4, IL6: interleukin-6, and IL10: interleukin-10 (see text for further details).

Figure 2. Cytokine levels in rat serum.

tively, the data from the LPS group shows an overall cytokine response promoting inflammation at 12 hours, whereas an anti-inflammatory response is dominating at 36 hours.

\subsection{Serum Biomarkers of Cardiac Damage and Inflammation Do Not Increase Concurrent with Cardiac rBD Up-Regulation}

To assess extent of potential cardiac damage and inflammation, we measured serum levels of cTnI (rat cardiac troponin I) and CRP (rat C-reactive protein) at the defined time-points. No statistically significant difference was observed among groups for neither cTnI nor CRP levels (Figure 3). Our findings indicate that the inflamematory mediators used in this study did not result in active cardiac damage, nor did they instigate a significant elevation in CRP levels.

\subsection{Animal Growth Rate and Lipid Profiling in High Fat Diet Feeding}

Serum cholesterol (TC, HDL and LDL) and triglyceride levels, relative growth rate and heart/body weight ratio were evaluated in the HFD group relative to controls. The average overall growth rate for the HFD group was $41 \mathrm{~g} /$ week versus $25 \mathrm{~g} /$ week for controls $(\mathrm{p}=0.016)$. Abdominal fat mass was on average 3.5 -fold higher in the HFD group versus control. The heart/body weight ratio was $0.3 \%-0.4 \%$ in both groups, and no significant difference was found in heart mass (Figure 4) between the HFD and control group $(p=0.67)$. The findings support that animals fed a HFD gained weight faster in addition to increased abdominal fat deposition. No gross difference was, however, seen in heart mass or pericardial fat deposition between groups. The lipid profiling showed a significant increase in serum triglyceride levels in the HFD group at the three weeks endpoint $(\mathrm{p}<0.001)$. Serum cholesterol fractions showed no difference in HDL levels between groups over the three weeks time period, while the LDL fraction was significantly different between groups at endpoint (Figure 5). Animals in the HFD group were hypertriglyceremic after 3 weeks on a diet containing $33 \%$ fat, but not (identifiably) hypercholesterolemic. 


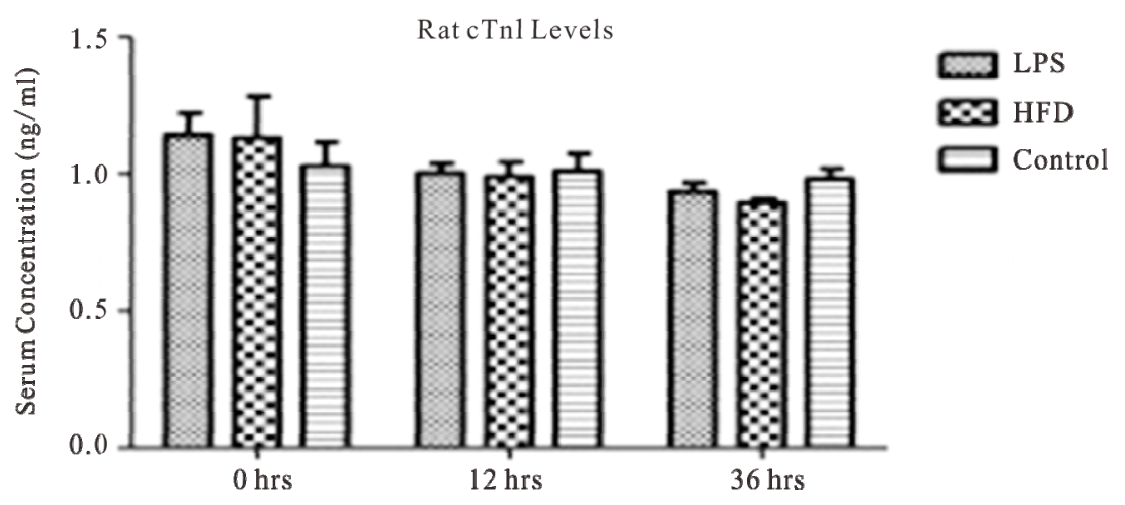

(a)

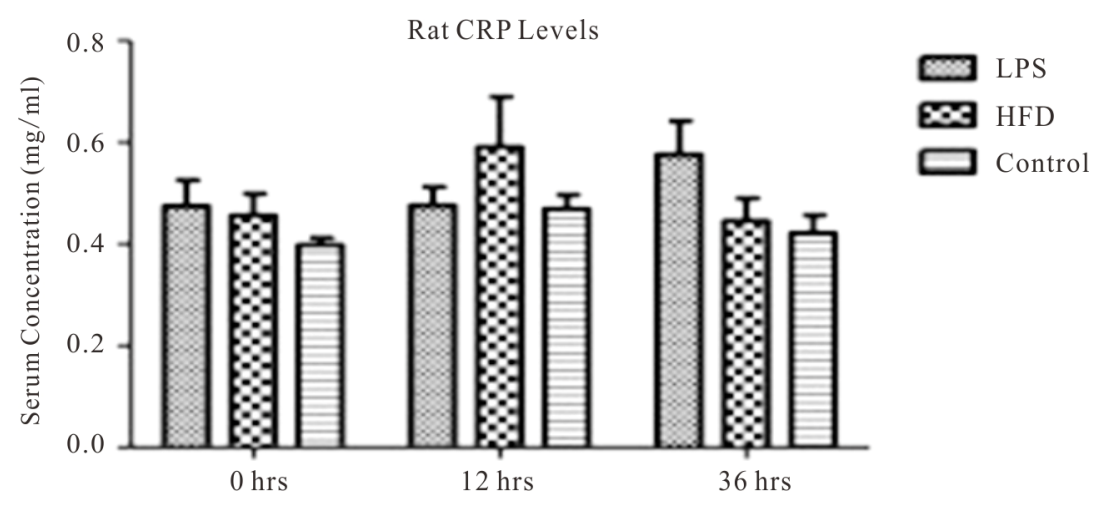

(b)

Top panel shows cardiac troponin-I (cTnI) levels $(\mathrm{ng} / \mathrm{ml})$ in rat serum from the LPS, HFD and control groups at baseline, 12 and $36 \mathrm{hrs}$, while the bottom panel reflects the C-reactive protein (CRP) serum levels $(\mathrm{mg} / \mathrm{ml})$ in the same animals. No difference was found within or among groups $(\mathrm{p}>0.05)$ for neither cTnI nor CRP. Serum CRP levels in normal rats are significantly higher compared to other species, and even exceed max.acute phase levels of CRP in humans [66].

Figure 3. Biochemical serum marker analysis for cardiac damage and inflammation.

\subsection{Computational Modeling of Select rBDs Predicts Biological Activity}

Computational analysis was performed to model the structure of select beta-defensin peptides, and predict functional characteristics. We evaluated the rBD10 and rBD11 peptides, because these exhibited the highest foldincrease $(>250)$ in gene-expression in response to the inflammatory mediators used in the study. The peptide modeling showed a similar shape in the structure for $\mathrm{rBD} 10$ and rBD11 (Figure 6). However, the surface electrostatic profiles for the two peptides were found to be substantially different, as were their charges-rBD10 possess five cationic groups and three anions for a net charge of +2 , while rBD11 has six cationic groups and no anions for a net charge of +6 . Moreover, charged positions were only found conserved in one position (at the C-terminus) along their mutual alignment. From the computational modeling it was also noted that unlike other HDPs, the selected rBDs possess no large contiguous lipophilic surface, which makes it less likely for either of these defensins to

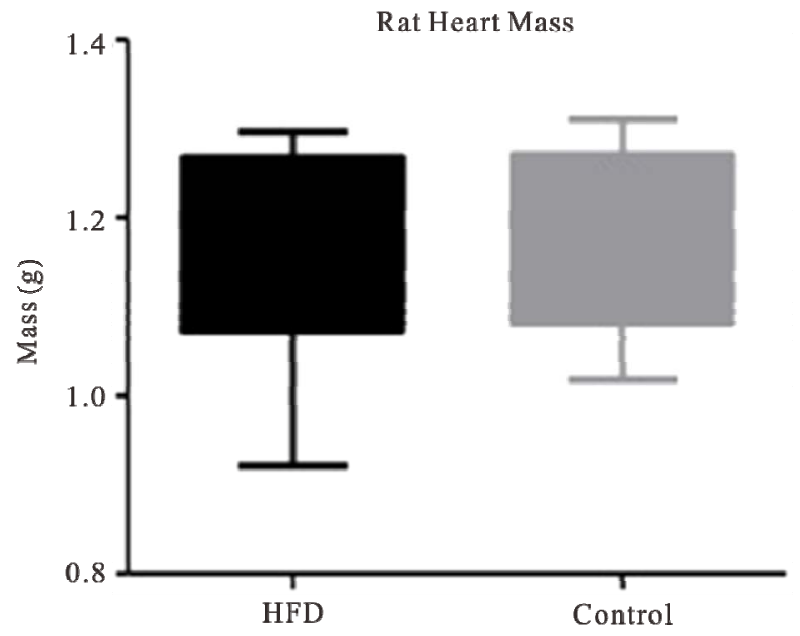

Figure 4. Comparison of heart size in rats exposed to a highfat diet versus controls $(\mathrm{p}>0.05)$.

bind really effectively to a lipid membrane. The large number of charged surface amino acids on both these species would moreover make it more likely that they 

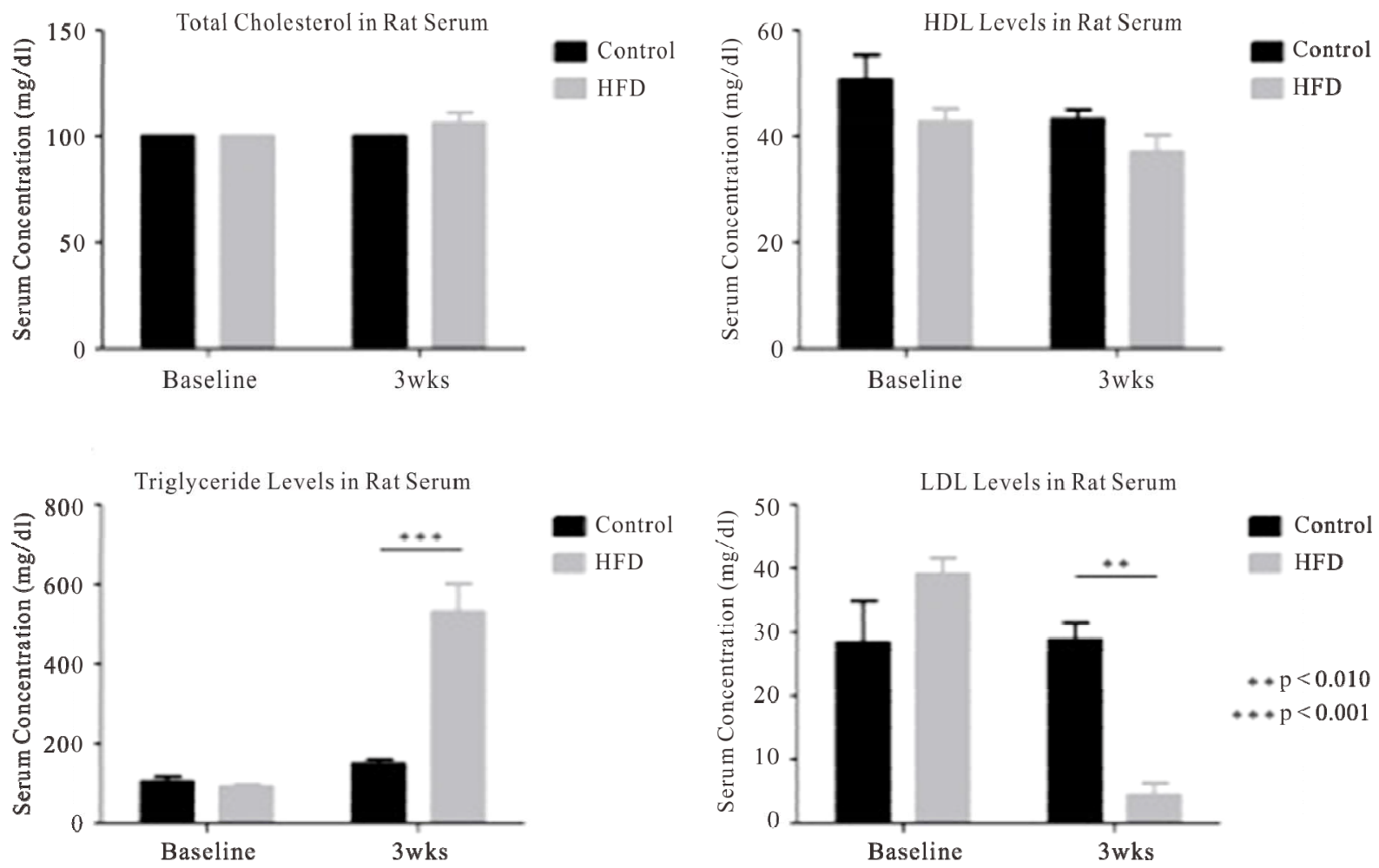

Total cholesterol, triglyceride, high-density lipoprotein (HDL) and low-density lipoprotein (LDL) cholesterol levels in rat serum at baseline and endpoint ( 3 weeks) for the HFD and control groups. The HFD group exhibited hypertriglyceremia after 3 weeks ( $<0.001$ vs control). No difference was seen in total cholesterol or HDL levels $(p>0.05)$, while a statistically significant difference between LDL levels was seen at the study endpoint $(\mathrm{p}<0.01)$.

Figure 5. Lipid profiles in HFD and control animals.

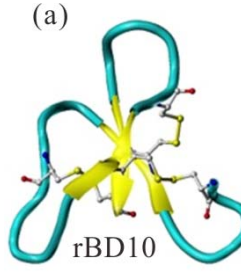

(b)

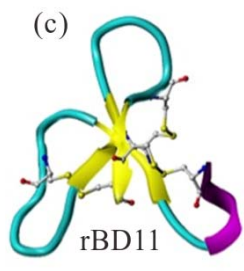

(d)
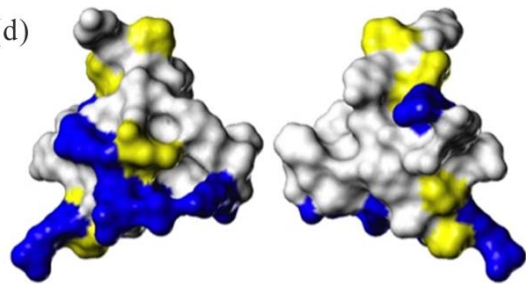

The figure displays secondary structure assignment and surface analysis for the selected cardiac rat beta-defensins rBD-10 and -11 . The ribbon diagrams (leftmost column) show beta-sheet (yellow), alpha-helix (purple) and coil (turquoise) secondary structure elements for each of the rBD peptides. The ball-and-stick structures depict disulphide bonds. Note that the absence of an alpha-helix in one peptide is also seen with certain beta-defensins from other species (e.g. hBD1 in humans). The calotte (space filling) models (middle and rightmost columns) depict front and rear views of peptide solvent accessible surfaces, including anionic/acidic (red), cationic/basic (blue), and hydrophobic (yellow) residues.

Figure 6. Computational modeling of cardiac rBDs.

interact via salt-bridge formation with proteins on target surfaces.

\subsection{Evaluation of Cardiac rBD Antimicrobial Activity against Select Bacterial Strains}

The antimicrobial activity of synthetic rBDs was assessed using pathogens previously associated with bacterial infections of the heart [26-28], including Gram-positive (Listeria monocytogenes and Staphylococcus aureus), and Gram-negative (Escherichia coli) strains. The final purity of the synthetic peptides was $>95 \%$ with a molecular mass of 3601.56 Da (rBD10), 3802.64 Da (rBD11), and $3662.45 \mathrm{Da}$ (rBD33). We assessed the minimal inhibitory concentration (MIC) of the synthetic rBD peptides against the abovementioned bacterial strains. Neither of the tested peptides exhibited antimicrobial activity against the selected pathogens (all MICs $>0.5 \mathrm{mg} / \mathrm{ml}$ ).

\subsection{Assessment of Cell Migration in Response to Select Cardiac rBDs}

Cardiac rBD gene-expression was markedly increased in rats after high-fat diet feeding. Because hyperlipidemia is a risk factor in the development of CVD, we assessed the effect of synthetic rBDs on inflammatory cell migration. The migration of rat neutrophils and monocytes in re- 
sponse to rBDs at different peptide concentrations as compared to controls was evaluated. Neutrophils showed no cell-migration activity, while monocytes migrated towards rBDs at different concentrations (Figure 7). Compared to controls, rBD10 produced a statistically significant $(\mathrm{p}<$ 0.001 ) increase in monocyte migration at concentrations from 1.0 to $100 \mathrm{ng} / \mathrm{ml}$ (including an approximately fourfold increase at $10 \mathrm{ng} / \mathrm{ml})$. The rBD11 and rBD33 peptides increased monocyte migration more than two-fold at $10 \mathrm{ng} / \mathrm{ml}$, which persisted at $100 \mathrm{ng} / \mathrm{ml}$ for rBD11.

\section{DISCUSSION}

With cardiovascular disease remaining a leading cause of death worldwide, novel preventative and therapeutic measures are still urgently needed to further advance the field. It is well recognized that inflammation plays a central role in the development and progression of cardiovascular pathology $[18,19,29,30]$, and also that the heartlike other organs in the body-possesses an intrinsic stress response system reacting specifically to diverse types of tissue injury [31-33]. Furthering the understanding of the myriad of elements involved in this potentially deleterious process is crucial to successfully identify templates for novel cardiac drugs, or new strategies aimed at heart disease prevention. The challenge - perhaps particularly in reference to cardioimmunology-remains to aptly distinguish causative relationships from epiphenomena.

In this study, we show that the rat myocardium exhibit constitutive expression of at least one type of HDPs-here referenced as cardiac beta-defensins-and that the geneexpression levels of these peptides change in response to

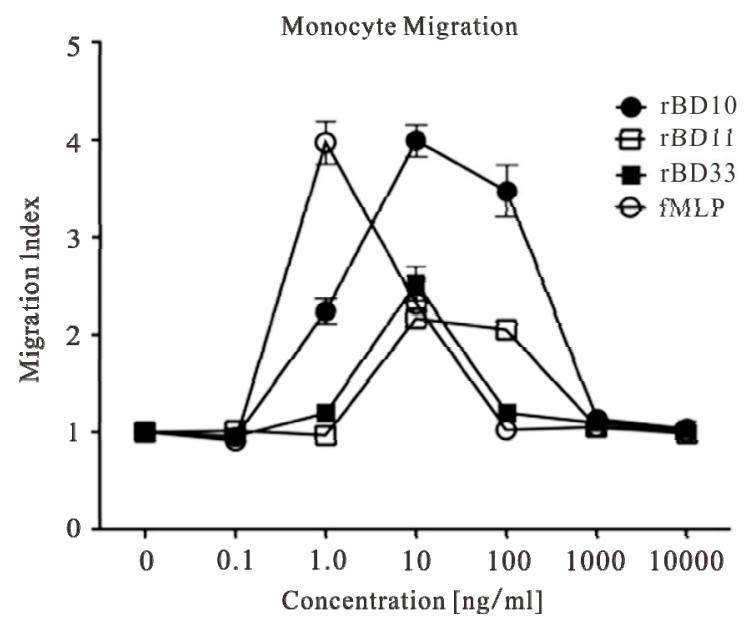

The figure shows the migratory response of rat monocytes towards rBD10 (black circle), rBD11 (clear square), rBD33 (black square), and the positive control fMLP (clear circle) at peptide concentrations ranging from $10,000 \mathrm{ng} / \mathrm{ml}$ to $0 \mathrm{ng} / \mathrm{ml}$ (negative control/medium only). The migration index (based on five microscopy fields and triplicate wells) is calculated as the $n$-fold change in cell migration in the presence of chemo-attractant as compared to cell migration resulting from medium only (negative control) [67].

Figure 7. Cell Migration to Cardiac-Derived rBDs. inflammatory mediators. The results suggest that cardiac beta-defensin expression is highly responsive to high fat diet feeding, and to a lesser (statistically non-significant) extent to LPS exposure. Other studies have reported enhanced [34] or reduced [35] beta-defensin gene-expression in disease states. Still, the current study is the first to evaluate beta-defensin expression in the myocardium in response to exogenous mediators of inflammation, and to further discuss the peptides' putative role in context of CVD.

Broadly defined, beta-defensins are typically upregulated by bacterial products as well as proinflammatory cytokines, while alpha-defensins are expressed on a more constitutive basis [36]. Induction of epithelial beta-defensin expression has also been reported secondary to stimulation with an essential amino acid, L-isoleucine [37]. A gap exists in the literature concerning beta-defensins' role in the heart, while neutrophil HDPs - including cathelicidins and alpha-defensins - have been implicated in atherosclerosis [15]. Alpha-defensins are released by activated or senescent neutrophils, which also contribute to various biochemical changes such as release of lysosomal enzymes as well as generation of oxygen radicals and hydrogen peroxide - in other words factors capable of altering vascular function [15,38]. A number of studies have as such focused on plasma alpha-defensins, and their potential role in cholesterol metabolism, vascular reactivity and neovascularization [13-16]. Even though the main site for alpha-defensins is within phagolysosomes of granulocytes, monocytes and natural killer cells, a portion of these peptides is also secreted into the circulation [36] - particularly upon neutrophil activation [14]. Studies have indicated that alpha-defensins act as inflammatory lipoprotein-binding apoproteins and modulate lowdensity lipoprotein metabolism by complex formation with LDL, thereby promoting surface binding of the resultant defensin/LDL - complexes to endothelial cells via heparan sulfate - containing proteoglycans (HSPGs) [3840] - a process that is heparin sensitive [38]. Retention of atherogenic lipoproteins within the vascular intima is fundamental to disease progression, which has associated alpha-defensins (in plasma) with cardiovascular morbidity and mortality [41], and plasma levels serve as a prognostic indicator of mortality in chronic heart failure patients [42].

Additionally, alpha-defensins may play a role in thrombotic microvascular occlusion by inhibiting the fibrinolytic activity of tissue plasminogen activator [43], and as regulators of angiogenesis through anti-proliferative and pro-apoptotic effects on endothelial cells [14]. This class of HDPs has moreover been implicated in endothelial dysfunction, and cutaneous alpha-defensin deposition has been suggested as a strong independent predictor of coronary artery disease [44]. Plasma alpha-defensin levels 
can increase up to 1000 -fold in infectious disease processes, with plasma-concentrations of greater than 150 $\mathrm{mg} / \mathrm{L}$ found in plasma during bacterial infections [45], compared to normal levels of approximately $200 \mu \mathrm{g} / \mathrm{L}$ [46]. Concentrations of defensins in neutrophil granules can, however, be as high as $10 \mathrm{mg} / \mathrm{ml}$ [47]. Another HDP - the iron-regulatory peptide hepcidin-was recently identified in rat myocardium, where it may play a role in development of cardiac disease secondary to iron overload [48].

In light of alpha-defensins' association with atherosclerosis and thrombosis [41], it is plausible that beta-defensins also impact cardiovascular homeostasis. Whether their biological role is primarily adverse or protective of heart health still remains to be defined. A recent study established that myocardial tissue and cardiac fibroblasts upregulate mRNA expression of cathelicidin and betadefensin- 2 in response to hypoxia, and that this may facilitate homing of stem/progenitor cells to the heart in patients with acute myocardial infarction (AMI), thus constituting a response of a more healing nature [49]. Additionally, a method for CVD risk assessment using genetic variation in a defensin gene has been patented [50].

Here, we found that rat monocytes attract to myocardial rBDs that are upregulated in response to HFD feeding. Mobilization of monocytes would, in a purely classical context, create cause for concern given their link to development of atherosclerosis. The population of monocytes is, however, more heterogenous that what was originally thought, and it is becoming increasingly clear that the functional capacity of these cells is multifaceted [51]. Monocytes' potential role as endothelial progenitor cells has been also mentioned, suggesting an ability to promote vascular tissue repair [51]. The plasticity of this cell population does present a challenge when trying to define one role for monocytes in cardiovascular disease, and monocyte activation could plausibly hold therapeutic potential.

LPS exposure and a high fat diet are factors that promote inflammation, and HFD alone can lead to metabolic endotoxemia-which positions LPS as a potential inflamematory factor in metabolic diseases [52]. This is complementary to reports showing that free fatty acids can bind to Toll-like receptor (TLR)-4, thus promoting cytokine release and inflammation [53]. The relevance of TLRs in heart failure, ventricular remodeling after acute myocardial infarction, and cardiac dysfunction secondary to endotoxemia has been previously reported [20,54-57]. The classical receptor for LPS is TLR4, which is expressed on cardiac myocytes [20]. However, it is seemingly the TLR4 on leukocytes (not cardiomyocytes) that is involved in myocardial depression during endotoxemia [20]. Since NF $\kappa$ B pathway signaling is also involved with beta-defensin transcription, limited TLR4 activation in cardiomyocytes might in part explain the limited increase in cardiac rBD gene-expression that we observed in the LPS group in this study.

To assess the systemic inflammatory response and potential concurrent cardiac injury, we moreover assessed serum levels of rat CRP, high sensitivity cTnI, and nine cytokines as well as serum lipid fractions. We found that serum levels in the high fat diet group were consistent with an inflammatory cytokine response and hypertriglyceridemia-both risk factors associated with CVD. Levels of HDL-cholesterol showed no differences between groups over time, while LDL was significantly lower in the HFD group as compared to controls at the study endpoint. No evidence of active cardiac damage was found based on cTnI serum levels alone, and CRP levels showed no statistical difference among groups. The findings suggest that although inflammatory mediators were administered, the amount was insufficient to cause marked systemic inflammation with active myocardial damage. Whether these findings are positively related to the enhanced gene-expression of cardiac rBDs remains unknown. Still, our data might suggest that increased cardiac rBD levels are associated with a less atherogenic lipid profile (perhaps from complex formation with LDL, and lowering of serum levels). It is thus plausible that these HDPs modulate the immune response to counteract the deleterious effects of chronic low-grade inflammation. Moreover, inhibition of the NF $\mathrm{BB}$ pathway leads to enhanced severity of atherosclerosis in LDL-receptor deficient mice [58]findings that could (theoretically) support an indirect cardioprotective effect of beta-defensin production (in light of intact NF $\kappa \mathrm{B}$ signaling) that is independent of LDL levels, or uptake.

Functional characteristics, including the antimicrobial capabilities of the two cardiac rBDs (rBD10/rBD11) that showed the highest up-regulation, were also evaluated via computational modeling. Defensins typically contain hydrophobic patches, which insert into the lipid portion of cell membranes [15]. Our computational modeling, however, suggests that neither of these rBDs would be highly likely to engage in lipid membrane binding. Based on a fairly large number of charged surface amino acids within these peptides' structure, it would be more likely for these peptides to interact via salt-bridge formation with proteins on target surfaces. A potentially important difference between rBD10 and rBD11, nonetheless, lies in the fact that the latter has five tyrosines (a rather unique finding for a BD), while the first possesses none. Tyrosine is moderately water soluble, but also potentially lipophilic because the hydroxyl may form a hydrogen bond with the lipid head groups, while the aryl interacts with the hydrocarbon-a composition that might make rBD11 sufficiently amphipathic to actually interact with the membrane, and as such support it having some level 


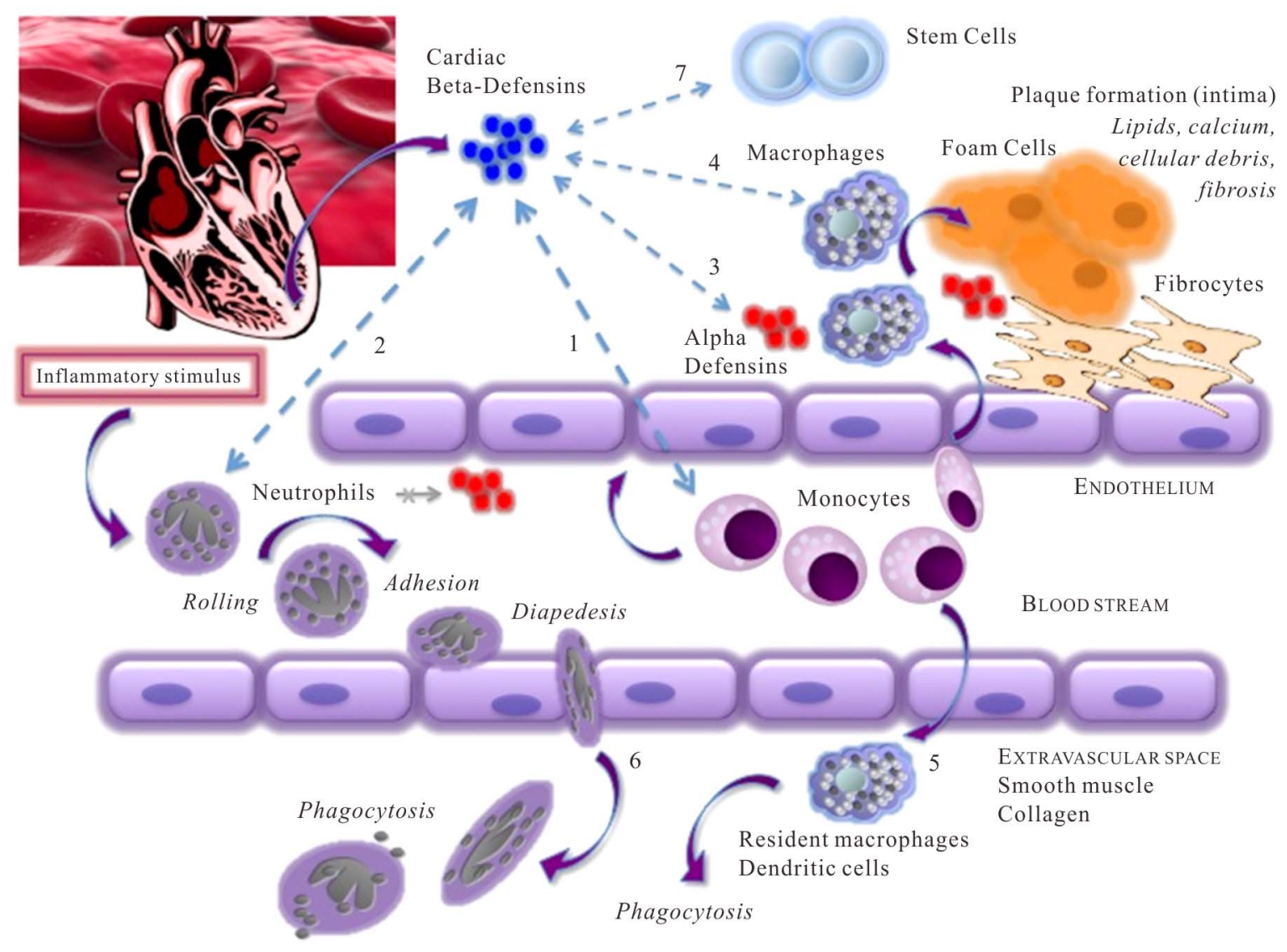

The figure shows proposed/hypothetical routes by which cardiac beta-defensins may exhibit a beneficial effect on the heart-i.e. in contrast to alpha-defensins' adverse impact on the vasculature. We refer broadly to "cardiac beta-defensins", although different defensins are likely to exert variable roles. While our findings support that select cardiac BDs can impact monocyte migration, and others [49] have shown that BD can facilitate homing of stem cells to the ischemic myocardium, the figure content is otherwise speculative in nature. The proposed actions for cardiac beta-defensins are as follows: (1) Promote recruitment of monocytes to e.g. facilitate vascular repair; (2) Impact neutrophils to e.g. inhibit cellular release of alpha-defensins; (3) Inhibit the actions of alpha-defensins, either alone or involving LDL; (4) Counteract the transition of monocytes/macrophages into foam cells; (5) Redirect monocytes towards transition into resident tissue macrophages or dendritic cell types; (6) Act on endothelial receptors to enhance leukocyte transmigration and phagocytic activity; (7) Facilitate homing of stem cells to the heart [figure includes MS Office clipart].

Figure 8. Proposed model for the role of beta-defensins in the heart.

of antimicrobial activity. Computational modeling also revealed significant differences in surface electrostatic profiles and net charges, which would imply that the rBD peptides are less likely to consistently bind to identical sites on target cells.

Using synthetic analogues of three cardiac rBDs with the highest up-regulation (rBD10, 11 and 33), we moreover evaluated the in vitro antimicrobial activity. All MICs were found to be in excess of $0.5 \mathrm{mg} / \mathrm{ml}$, suggesting that the chosen rBDs exhibit no detectable antimicrobial activity against the selected microorganisms, as compared to other more potent HDPs [47]. It still remains questionable, however, whether other cardiac rBDs might exhibit antimicrobial activity towards pathogens of relevance to development of CVD. Experimental studies by others have previously confirmed that the cardiac dysfunction observed in Gram-negative sepsis is also en- countered in cases with Gram-positive sepsis [31], and that TLR2 signaling interferes with cardiac function in Staphylococcus aureus (Gram-positive) sepsis [31]. It is possible that a more pronounced $\mathrm{rBD}$ response would result from in vivo stimulation with LTA (lipoteichoic acid from the Staph aureus cell wall), versus what we observed using LPS exposure (i.e. Gram-negative cell wall component).

The relationship between structure and biological function in beta-defensin peptides has been studied [59-61], and it is known that the bactericidal activity of BDs remains unaffected in the absence of disulfide bridges, whereas the chemotactic activity is abolished with cysteine substitution [61]. A number of defensins is known to act as chemoattractants at nanomolar concentrations, exhibiting activity towards a variety of different cell types, including monocytes, neutrophils, CD4+ T-cells and im- 
mature dendritic cells $[60,62]$, although anti-chemotactic activity towards leukocytes has been reported also [63]. Here, we assessed the activity of select rBDs as chemoattractants for circulatory cells. While we did not observe any migratory activity of neutrophils in response to the rBDs, we found that the tested peptides (rBD10, 11 and 33) exert significant chemoattraction of monocytes. One factor that substantially affects a peptide's role in chemotaxis is the peptide's ability to bind to a given cellular chemotaxis receptor. In the case of defensins, CCR6 has been mentioned as the chemokine receptor (CCR) through which the peptides exert their chemoattractive function [60]. Additional receptors are also at play since defensininduced cell migration has been reported with cells that do not express functional CCR6-such as monocytes [64]. More recently it was found that defensins also interact with the CCR2 chemokine receptor (which is expressed by monocytes, as well as macrophages and neutrophils) [65]. Our evaluation of the shape of the select rBDs-and this being very similar to most other defensins-support that these permit binding to such chemokine receptors with a binding efficacy that will depend somewhat on how electrostatically and lipophilically compatible a given peptide is to a given receptor. The cardiac rBD peptides in question are substantially different from e.g. the human defensins in this regard, and would as such be anticipated to exhibit some differences in their chemoattractive profiles relative to these defensins (as well as relative to one another). Importantly, the relationship between structure and function in defensins highlights the possibility of engineering these peptides to enhance their future potential as therapeutic agents.

\section{CONCLUSIONS}

The broad lesson to be learned is that the perceived role of beta-defensins (and other HDPs) without doubt has broadened in the last decade or more, from being mere natural antibiotic peptides to multifunctional effector molecules of the immune system. Activation of the immune system can undoubtedly be regarded as a double-edged sword. While the potential salutary effects of rBDs in the heart and vasculature remain to be defined, it is conceivable that cardiac rBDs contribute to the immune response against dangers in an effort to heal injured cardiac tissue (Figure 8). Also, seemingly minor individual effects in expression of different HDPs may in combination be biologically relevant. It therefore remains uncertain if cardiac rBD "over-expression" acts to preserve heart health or is causally linked to development of CVD, or if the peptides are mostly molecular bystanders in this context.

In conclusion, we demonstrate that rBDs are expressed intrinsically by the myocardium. Additionally, we show that this gene-expression is modified under the influence of inflammatory mediators. We furthermore present computational and in vitro data related to the functional properties of select cardiac rBDs as natural antibiotic and immunoregulatory peptides. Still, additional research is unquestionably warranted to help further untangle the molecular web of the cardiovascular system in disease and health.

\section{ACKNOWLEDGEMENTS \& FUNDING}

We acknowledge Nithya Raveendran (COBRE Core Facilities, Kansas State University) for technical assistance with the gene expression studies, Dmitry Yakovlev (Structural Biology Center, University of Kansas ) for synthesizing rBD peptides, and Tammy Koopman (Veterinary Diagnostic Laboratory, K-State) for conducting the FACS. We thank Amy Hanson, Lea Dib, Kate Osei-Boadi, and Brian Snyder for technical support, and Stephanie Barret and Sally Olson (Comparative Medicine Group, K-State) for valuable assistance with the animal studies. The work was supported by the Mentored Clinical, Applied, or Translational Research (MCAT) grant mechanism at K-State, College of Veterinary Medicine, Office of the Associate Dean for Research \& Graduate Programs, and the Dr. Albert L. Burrough's Memorial Fund. Support was also received from NIH grant P20-RR017686, and the K-State Center of Biomedical Research Excellence (COBRE).

\section{REFERENCES}

[1] Boman, H.G. (2003) Antibacterial peptides: Basic facts and emerging concepts. Journal of Internal Medicine, 254, 197-215. doi:10.1046/j.1365-2796.2003.01228.x

[2] Ganz, T. (2005) Defensins and other antimicrobial peptides: A historical perspective and an update. Combinatorial Chemistry \& High Throughput Screening, 8, 209-217. doi:10.2174/1386207053764594

[3] Linde, A., Mosier, D., Blecha, F. and Melgarejo, T. (2007) Innate immunity and inflammation-New frontiers in comparative cardiovascular pathology. Cardiovascular Research, 73, 26-36. doi:10.1016/j.cardiores.2006.08.009

[4] Davis, E.G., Sang, Y. and Blecha, F. (2004) Equine betadefensin-1: Full-length cDNA sequence and tissue expression. Veterinary Immunology and Immunopathology, 199, 127-132. doi:10.1016/j.vetimm.2003.12.010

[5] Garcia, J.R., Jaumann, F., Schulz, S., Krause, A., Rodriguez-Jimenez, J., Forssmann, U., Adermann, K., Kluver, E., Vogelmeier, C., Becker, D., Hedrich, R., Forssmann, W.G. and Bals, R. (2001) Identification of a novel, multifunctional beta-defensin (human beta-defensin 3 ) with specific antimicrobial activity. Its interaction with plasma membranes of Xenopus oocytes and the induction of macrophage chemoattraction. Cell and Tissue Research, 306, 257-264. doi: $10.1007 / \mathrm{s} 004410100433$

[6] Jia, H.P., Schutte, B.C., Schudy, A., Linzmeier, R., Guthmiller, J.M., Johnson, G.K., Tack, B.F., Mitros, J.P., Rosenthal, A., Ganz, T. and McCray, P.B.J. (2001) Discovery of new human beta-defensins using a genomics-based approach. Gene, 263, 211-218. doi:10.1016/S0378-1119(00)00569-2 
[7] Ma, D., Wang, R., Liao, W., Han, Z. and Liu, S. (2009) Identification and characterization of a novel antibacterial peptide, avian beta-defensin 2 from ducks. The Journal of Microbiology, 47, 610-618. doi:10.1007/s12275-009-0068-Z

[8] Morrison, G., Kilanowski, F., Davidson, D. and Dorin, J. (2002) Characterization of the mouse beta defensin 1 , Defb1, mutant mouse model. Infection and Immunity, 70, 3053-3060. doi:10.1128/IAI.70.6.3053-3060.2002

[9] Page, R.A. and Malik, A.N. (2003) Elevated levels of beta defensin-1 mRNA in diabetic kidneys of GK rats. Biochemical and Biophysical Research Communications, 310, 513-521. doi:10.1016/j.bbrc.2003.09.034

[10] Schutte, B.C. and McCray, P.B.J. (2002) Beta-defensins in lung host defense. Annual Review of Physiology, 64, 709-748. doi:10.1146/annurev.physiol.64.081501.134340

[11] Yang, Y., Wang, C., Zhao, Y. and Yu, X. (2009) Reindeer beta-defensin-1: Full-length cDNA cloning and tissue expression. Veterinary Immunology and Immunopathology, 131, 137-139. doi:10.1016/i.vetimm.2009.03.008

[12] Zhang, G., Wu, H., Shi, J., Ganz, T., Ross, C.R. and Blecha, F. (1998) Molecular cloning and tissue expression of porcine beta-defensin-1. FEBS Letters, 424, 37-40. doi:10.1016/S0014-5793(98)00134-3

[13] Barnathan, E.S., Raghunath, P.N., Tomaszewski, J.E., Ganz, T., Cines, D.B. and Higazi, A.-R. (1997) Immunohistochemical localization of defensin in human coronary vessels. American Journal of Pathology, 150, 1009-1020.

[14] Chavakis, T., Cines, D.B., Rhee, J.S., Liang, O.D., Schubert, U., Hammes, H.P., Higazi, A.A., Nawroth, P.P., Preissner, K. T. and Bdeir, K. (2004) Regulation of neovascularization by human neutrophil peptides (alpha-defensins): A link between inflammation and angiogenesis. The FASEB Journal, 18, 1306-1308. doi:10.1096/fj.03-1009fje

[15] Kougias, P., Chai, H., Lin, P.H., Yao, Q., Lumsden, A.B. and Chen, C. (2005) Defensins and cathelicidins: Neutrophil peptides with roles in inflammation, hyperlipidemia and atherosclerosis. Journal of Cellular and Molecular Medicine, 9, 3-10. doi:10.1111/j.1582-4934.2005.tb00332.x

[16] Lopez-Bermejo, A., Chico-Julia, B., Castro, A., Recasens, M., Esteve, E., Biarnes, J., Casamitjana, R., Ricart, W. and Fernandez-Real, J.M. (2007) Alpha defensins 1, 2, and 3: Potential roles in dyslipidemia and vascular dysfunction in humans. Arteriosclerosis, Thrombosis, and Vascular Biology, 27, 1166-1171. doi:10.1161/ATVBAHA.106.138594

[17] Doggrell, S.A. (2005) Recent advances in heart research. Drug News \& Perspectives, 18, 58-72.

[18] Libby, P., Ridker, P.M. and Maseri, A. (2002) Inflammation and atherosclerosis. Circulation, 105, 1135-1143. doi:10.1161/hc0902.104353

[19] Rader, D.J. and Daugherty, A. (2008) Translating molecular discoveries into new therapies for atherosclerosis. Nature, 451, 904-913. doi:10.1038/nature06796

[20] Baumgarten, G., Knuefermann, P., Nozaki, N., Sivasubramanian, N., Mann, D.L. and Vallejo, J.G. (2001) In vivo expression of proinflammatory mediators in the adult heart after endotoxin administration: The role of toll-like receptor-4. The Journal of Infectious Diseases, 183, 16171624. doi: $10.1086 / 320712$

[21] Thompson, J.D., Higgins, D.G. and Gibson, T.J. (1994) CLUSTAL W: Improving the sensitivity of progressive multiple sequence alignment through sequence weighting, position-specific gap penalties and weight matrix choice. Nucleic Acids Research, 22, 4673-4680.

doi:10.1093/nar/22.22.4673

[22] Sanchez, R. and Sali, A. (2000) Comparative protein structure modeling. Introduction and practical examples with modeller. Methods in Molecular Biology, 143, $97-$ 129. doi:10.1385/1-59259-368-2:97

[23] Wiegand, I., Hilpert, K. and Hancock, R.E. (2008) Agar and broth dilution methods to determine the minimal inhibitory concentration (MIC) of antimicrobial substances. Nature Protocols, 3, 163-175. doi:10.1038/nprot.2007.521

[24] Wikler, M.A., Cockerill, F.R., Craig, W.A., Dudley, M.N., Eliopoulos, G.M., Hecht, D.W., Hindler, J.F., Ferraro, M.J., Swenson, J.M., Low, D.E., Sheehan, D.J., Tenover, F.C., Turnidge, J.D., Weinstein, M.P. and Zimmer, B.L. (2006) Methods for dilution antimicrobial susceptibility tests for bacteria that grow aerobically; approved standard-seventh edition. Clinical and Laboratory Standards Institute Report No. M7-A7.

[25] Linde, A., Lushington, G.H., Blecha, F. and Melgarejo, T. (2008) Rat cardiomyocytes express a classical epithelial beta-defensin. American Journal of Animal and Veterinary Sciences, 3, 1-6. doi:10.3844/ajavsp.2008.1.6

[26] Branger, S., Casalta, J.P., Habib, G., Collard, F. and Raoult, D. (2005) Escherichia coli endocarditis: Seven new cases in adults and review of the literature. European Journal of Clinical Microbiology \& Infectious Diseases, 24, 537 541. doi:10.1007/s10096-005-1379-6

[27] Naber, C.K. (2008) Future strategies for treating Staphylococcus aureus bloodstream infections. Clinical Microbiology and Infection, 14, 26-34. doi:10.1111/j.1469-0691.2008.01924.x

[28] Spyrou, N., Anderson, M. and Foale, R. (1997) Listeria endocarditis: Current management and patient outcomeworld literature review. Heart, 77, 380-383.

[29] Knuefermann, P., Nemoto, S., Baumgarten, G., Misra, A., Sivasubramanian, N., Carabello, B.A. and Vallejo, J.G. (2002) Cardiac inflammation and innate immunity in septic shock: Is there a role for toll-like receptors? Chest, 121, 1329-1336. doi:10.1378/chest.121.4.1329

[30] Ross, R. (1993) The pathogenesis of atherosclerosis: A perspective for the 1990s. Nature, 362, 801-809. doi: $10.1038 / 362801 \mathrm{a} 0$

[31] Knuefermann, P., Sakata, Y., Baker, J.S., Huang, C.H., Sekiguchi, K., Hardarson, H.S., Takeuchi, O., Akira, S. and Vallejo, J.G. (2004) Toll-like receptor 2 mediates Staphylococcus aureus-induced myocardial dysfunction and cytokine production in the heart. Circulation, 110, 36933698. doi:10.1161/01.CIR.0000143081.13042.04

[32] Matzinger, P. (2007) Friendly and dangerous signals: Is 
the tissue in control? Nature Immunology, 8, 11-13. doi:10.1038/ni0107-11

[33] Raz, E. (2007) Organ-specific regulation of innate immunity. Nature Immunology, 8, 3-4. doi:10.1038/ni0107-3

[34] Stryjewski, M.E., Hall, R.P., Chu, V.H., Kanafani, Z.A., O'Riordan, W.D., Weinstock, M.S., Stienecker, R.S., Streilein, R., Dorschner, R.A., Fowler, V.G.J., Corey, G.R. and Gallo, R.L. (2007) Expression of antimicrobial peptides in the normal and involved skin of patients with infective cellulitis. The Journal of Infectious Diseases, 196, 14251430. doi: $10.1086 / 522630$

[35] Abedin, A., Mohammed, I., Hopkinson, A. and Dua, H.S. (2008) A novel antimicrobial peptide on the ocular surface shows decreased expression in inflammation and infection. Investigative Ophthalmology \& Visual Science, 49, 28-33. doi:10.1167/iovs.07-0645

[36] Selsted, M.E. and Ouellette, A.J. (2005) Mammalian defensins in the antimicrobial immune response. Nature Immunology, 6, 551-557.

[37] Fehlbaum, P., Rao, M., Zasloff, M. and Anderson, G.M. (2000) An essential amino acid induces epithelial betadefensin expression. Proceedings of the National Academy of Sciences of the United States of America, 97, 12723-12728. doi:10.1073/pnas.220424597

[38] Bdeir, K., Cane, W., Canziani, G., Chaiken, I., Weisel, J., Koschinsky, M.L., Lawn, R.M., Bannerman, P.G., Sachais, B.S., Kuo, A., Hancock, M.A., Tomaszewski, J., Raghunath, P.N., Ganz, T., Higazi, A.A. and Cines, D.B. (1999) Defensin promotes the binding of lipoprotein (a) to vascular matrix. Blood, 94, 2007-2019.

[39] Higazi, A.A., Lavi, E., Bdeir, K., Ulrich, A.M., Jamieson, D.G., Rader, D.J., Usher, D.C., Kane, W., Ganz, T. and Cines, D.B. (1997) Defensin stimulates the binding of lipoprotein (a) to human vascular endothelial and smooth muscle cells. Blood, 89, 4290-4298.

[40] Higazi, A.A., Nassar, T., Ganz, T., Rader, D.J., Udassin, R., Bdeir, K., Hiss, E., Sachais, B.S., Williams, K.J., Leitersdorf, E. and Cines, D.B. (2000) The alpha-defensins stimulate proteoglycan-dependent catabolism of lowdensity lipoprotein by vascular cells: A new class of inflammatory apolipoprotein and a possible contributor to atherogenesis. Blood, 96, 1393-1398.

[41] Joseph, G., Tarnow, L., Astrup, A.S., Hansen, T.K., Parving, H.H., Flyvbjerg, A. and Frystyk, J. (2008) Plasma alpha-defensin is associated with cardiovascular morbidity and mortality in type 1 diabetic patients. The Journal of Clinical Endocrinology \& Metabolism, 93, 14701475. doi:10.1210/jc.2007-1910

[42] Christensen, H.M., Frystyk, J., Faber, J., Schou, M., Flyvbjerg, A., Hildebrandt, P., Raymond, I., Klausen, T.W. and Kistorp, C. (2012) Alpha-defensins and outcome in patients with chronic heart failure. European Journal of Heart Failure, 14, 387-394. doi:10.1093/eurjhf/hfs021

[43] Higazi, A.A., Barghouti, I.I. and Abu-Much, R. (1995) Identification of an inhibitor of tissue-type plasminogen activator-mediated fibrinolysis in human neutrophils. A role for defensin. Journal of Biological Chemistry, 270, 9472-9477.doi:10.1074/jbc.270.16.9472
[44] Nassar, H., Lavi, E., Akkawi, S., Bdeir, K., Heyman, S. N., Raghunath, P.N., Tomaszewski, J. and Higazi, A.A. (2007) Alpha-defensin: Link between inflammation and atherosclerosis. Atherosclerosis, 194, 452-457. doi:10.1016/j.atherosclerosis.2006.08.046

[45] Panyutich, A.V., Panyutich, E.A., Krapivin, V.A., Baturevich, E.A. and Ganz, T. (1993) Plasma defensin concentrations are elevated in patients with septicemia or bacterial meningitis. The Journal of Laboratory and Clinical Medicine, 122, 202-207.

[46] Ashitani, J., Mukae, H., Hiratsuka, T., Nakazato, M., Kumamoto, K. and Matsukura, S. (2002) Elevated levels of alpha-defensins in plasma and BAL fluid of patients with active pulmonary tuberculosis. Chest, 121, 519-526. doi:10.1378/chest.121.2.519

[47] Hancock, R.E. (2001) Cationic peptides: Effectors in innate immunity and novel antimicrobials. The Lancet Infectious Disease, 1, 156-164. doi:10.1016/S1473-3099(01)00092-5

[48] Merle, U., Fein, E., Gehrke, S.G., Stremmel, W. and Kulaksiz, H. (2007) The iron regulatory peptide hepcidin is expressed in the heart and regulated by hypoxia and inflammation. Endocrinology, 148, 2663-2668. doi:10.1210/en.2006-1331

[49] Karapetyan, A.V., Klyachkin, Y.M., Selim, S., Sunkara, M., Ziada, K.M., Cohen, D.A., Zuba-Surma, E.K., Ratajczak, J., Smyth, S.S., Ratajczak, M.Z., Morris, A.J. and Abdel-Latif, A. (2013) Bioactive lipids and cationic antimicrobial peptides as new potential regulators for trafficking of bone marrow-derived stem cells in patients with acute myocardial infarction. Stem Cells and Development, 22, 1645-1656. doi:10.1089/scd.2012.0488

[50] Salonen, J.K., Pirskanen, M., Haarus, J., Tuomainen, T.P. and Yunus, F. (2007) Method for detecting the risk of cardiovascular diseases such as acute myocardial infarction and coronary heart disease by analyzing defensin. US Patent No. US2007/0299025 A1.

[51] Apostolakis, S., Lip, G.Y. and Shantsila, E. (2010) Monocytes in heart failure: Relationship to a deteriorating immune overreaction or a desperate attempt for tissue repair? Cardiovascular Research, 85, 649-660. doi:10.1093/cvr/cvp327

[52] Cani, P.D., Amar, J., Iglesias, M.A., Poggi, M., Knauf, C., Bastelica, D., Neyrinck, A.M., Fava, F., Tuohy, K.M., Chabo, C., Waget, A., Delmee, E., Cousin, B., Sulpice, T., Chamontin, B., Ferrieres, J., Tanti, J.F., Gibson, G.R., Casteilla, L., Delzenne, N.M., Alessi, M.C. and Burcelin, R. (2007) Metabolic endotoxemia initiates obesity and insulin resistance. Diabetes, 56, 1761-1772. doi:10.2337/db06-1491

[53] Shi, H., Kokoeva, M.V., Inouye, K., Tzameli, I., Yin, H.

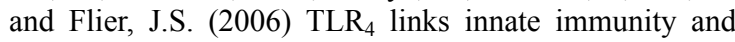
fatty acid-induced insulin resistance. The Journal of Clinical Investigation, 116, 3015-3025. doi:10.1172/JCI28898

[54] Frantz, S., Kobzik, L., Kim, Y.D., Fukazawa, R., Medzhitov, R., Lee, R.T. and Kelly, R.A. (1999) Toll (TLR $\left._{4}\right)$ expression in cardiac myocytes in normal and failing myocardium. The Journal of Clinical Investigation, 104, 


\section{1-280. doi:10.1172/JCI6709}

[55] Frantz, S., Kelly, R.A. and Bourcier, T. (2001) Role of TLR-2 in the activation of nuclear factor kappaB by oxidative stress in cardiac myocytes. Journal of Biological Chemistry, 276, 5197-5203. doi:10.1074/jbc.M009160200

[56] Shishido, T., Nozaki, N., Yamaguchi, S., Shibata, Y., Nitobe, J., Miyamoto, T., Takahashi, H., Arimoto, T., Maeda, K., Yamakawa, M., Takeuchi, O., Akira, S., Takeishi, Y. and Kubota, I. (2003) Toll-like receptor-2 modulates ventricular remodeling after myocardial infarction. Circulation, 108, 2905-2910. doi:10.1161/01.CIR.0000101921.93016.1C

[57] Tavener, S.A., Long, E.M., Robbins, S.M., McRae, K.M., Van Remmen, H. and Kubes, P. (2004) Immune cell Tolllike receptor 4 is required for cardiac myocyte impairment during endotoxemia. Circulation Research, 95, 700707. doi:10.1161/01.RES.0000144175.70140.8c

[58] Kanters, E., Pasparakis, M., Gijbels, M.J., Vergouwe, M. N., Partouns-Hendriks, I., Fijneman, R.J., Clausen, B.E., Forster, I., Kockx, M.M., Rajewsky, K., Kraal, G., Hofker, M.H. and de Winther, M.P. (2003) Inhibition of NF-kap$\mathrm{paB}$ activation in macrophages increases atherosclerosis in LDL receptor-deficient mice. The Journal of Clinical Investigation, 112, 1176-1185. doi:10.1172/JCI18580

[59] Lourenzoni, M.R., Namba, A.M., Caseli, L., Degreve, L. and Zaniquelli, M.E. (2007) Study of the interaction of human defensins with cell membrane models: Relationships between structure and biological activity. The Journal of Physical Chemistry B, 111, 11318-11329. doi:10.1021/jp067127g

[60] Taylor, K., Barran, P.E. and Dorin, J.R. (2008) Structure-activity relationships in beta-defensin peptides. Peptide Science, 90, 1-7. doi:10.1002/bip.20900

[61] Wu, Z., Hoover, D.M., Yang, D., Boulegue, C., Santamaria, F., Oppenheim, J.J., Lubkowski, J. and Lu, W. (2003) Engineering disulfide bridges to dissect antim- icrobial and chemotactic activities of human beta-defen$\sin 3$. Proceedings of the National Academy of Sciences of the United States of America, 100, 8880-8885. doi:10.1073/pnas.1533186100

[62] Territo, M.C., Ganz, T., Selsted, M.E. and Lehrer, R. (1989) Monocyte-chemotactic activity of defensins from human neutrophils. The Journal of Clinical Investigation, 84, 2017-2020. doi:10.1172/JCI114394

[63] Grutkoski, P.S., Graeber, C.T., Lim, Y.P., Ayala, A. and Simms, H.H. (2003) Alpha-defensin 1 (human neutrophil protein 1) as an antichemotactic agent for human polymorphonuclear leukocytes. Antimicrobial Agents and Chemotherapy, 47, 2666-2668. doi:10.1128/AAC.47.8.2666-2668.2003

[64] Soruri, A., Grigat, J., Forssmann, U., Riggert, J. and Zwirner, J. (2007) Beta-defensins chemoattract macrophages and mast cells but not lymphocytes and dendritic cells: CCR6 is not involved. European Journal of Immunology, 137, 2474-2486. doi:10.1002/eji.200737292

[65] Rohrl, J., Yang, D., Oppenheim, J.J. and Hehlgans, T. (2010) Human beta-defensin 2 and 3 and their mouse orthologs induce chemotaxis through interaction with CCR2. The Journal of Immunology, 184, 6688-6694. doi:10.4049/jimmunol.0903984

[66] de Beer, F.C., Baltz, M.L., Munn, E.A., Feinstein, A., Taylor, J., Bruton, C., Clamp, J.R. and Pepys, M.B. (1982) Isolation and characterization of C-reactive protein and serum amyloid $\mathrm{P}$ component in the rat. Immunology, 45, 55-70.

[67] Garcia, J.R., Krause, A., Schulz, S., Rodriguez-Jimenez, F.J., Kluver, E., Adermann, K., Forssmann, U., Frimpong-Boateng, A., Bals, R. and Forssmann, W.G. (2001) Human beta-defensin 4: A novel inducible peptide with a specific salt-sensitive spectrum of antimicrobial activity. The FASEB Journal, 15, 1819-1821. doi:10.1096/fj.00-0865fje

\section{ABBREVIATIONS}

AMI: acute myocardial infarction

BSA: bovine serum albumin

CVD: cardiovascular disease

FACS: fluorescence-activated cell sorting

fMLP: formyl-Methionyl-Leucyl-Phenylalanine

HDL: high density lipoprotein

IACUC: institutional animal care and use committee

K-State: Kansas State University, KSU

LDL: low density lipoprotein

PVP: polyvinylpyrrolidone

RPMI: Roswell Park Memorial Institute (medium)

TC: total cholesterol 